\title{
Relationship Between Peer Attachment and Adolescent Positive Well-Being with Gender as the Moderating Factor in Malaysia
}

\author{
Kogilavani Rajendran \\ PhD in Psychology, Psychology Officer, Police Headquarters, Kuala Lumpur, \\ Malaysia. \\ Gunasegaran Karuppannan \\ $\mathrm{PhD}$ in Education, Associate Professor, Deputy Dean of CGS, Universiti Selangor, \\ Malaysia. \\ Rumaya Binti Juhari \\ PhD in Psychology, Professor in the Faculty of Human Ecology, \\ Universiti Putra Malaysia \\ Asnia Kadir \\ EdD in Education, School Improvement Specialist Coaches, \\ Department of Education, Sabah, Malaysia. \\ Rosnah Jamba \\ EdD in Education, Teacher and Head of Mathematics Panel, \\ Secondary School, Sabah, Malaysia.
}

\section{Abstract}

Identifying protective factors that could influence the positive well-being of adolescents is important as positive development view emphasizes the possibility of adolescents developing positive traits based on their strengths, positive qualities, and supportive environments. This study examines the relationship between peer attachment with positive adolescent well-being and the role of gender as a moderator for links between peer attachment with positive adolescent well-being. A total of $4007^{\text {th }}$ Grade students from government schools in the Federal Territory of Kuala Lumpur and state of Selangor were involved in this study. Adolescent positive well-being and peer attachment were measured using the Positive Youth Development Scale and Inventory of Peer and Parent Attachment. The results show that peer attachment was predictor of adolescent positive well-being. The study also found that gender moderated the relationship between peer attachment and adolescent positive well-being. This study provides information on factors that can help the positive development of adolescents. Identifying these factors will provide insight on events or experiences that will increase the 
occurrence of positive outcomes and reduce the likelihood of negative outcomes.

Keywords: Influence, positive traits, strengths, positive qualities, and supportive environments

\section{Introduction}

The positive development approach provides an alternative view in the developmental literature in addressing the issue of risky and problematic behaviour (Lerner et al., 2011). This view emphasizes the possibility of adolescents following positive development based on their strengths and skills, and on conducive environments. Adolescents with positive development not only have less problematic behaviours but also show an increased tendency in making contributions to their positive well-being (Lerner et al., 2011). A positive perspective on adolescent development has been reinforced over the past two decades (Geldhof et al., 2013).

Background of the Study

In a comprehensive review of adolescent issues that take into account the risk factors, studies (Allen \& Waterman, 2019) have found that the period of 'early adolescence' is defined as the period between 11-14 years of age. During this time, adolescents would experience changes in their feelings, cognition and body (Lerner, 2005) and these changes are deemed to contribute to affecting the positive well-being of adolescents (Koepke \& Denissen 2012; McElhaney \& Allen 2012).

A study by Lee (2010) showed that the number of Malaysian adolescents diagnosed with stress and depression increased from $13 \%$ in 1996 to $20.3 \%$ in 2006, while Wong and Lua (2011) found the prevalence of mild anxiety and depression at $12.9 \%$ and $11.3 \%$ in 2011. The Department of Statistics Malaysia (2016) noted that in 2015 adolescents were involved in $36 \%$ of property-related crimes, $29.7 \%$ with drugs, and $13.4 \%$ in people-related crimes such as assault, molestation and rape. These statistics shows the level of social problems involving adolescents in Malaysia and it would appear that more adolescents in Malaysia experience emotional problems such as depression, anxiety, and aggression. Reasons attributing to such behaviours include poor peer attachment (Millings, et al., 2012; Oldfield, Humphrey \& Hebron, 2016).

Familial and social relationships have been found to be an important source for positive development of adolescents (Youngblade et al., 2007). Bornstein, Hahn and Hayness (2012) report that a number of positive familial and social characteristics are related to adolescent adjustment, self-esteem, academic success, social competence, and a decrease in both externalizing and internalizing problems in adolescents. Adolescents experiencing positive development is essential if they are to lead meaningful and fulfilling lives to enhance what is best in themselves.

Peer attachment is essential in the development of the emotional and social 
competence of adolescents especially in the school environment. Positive judgments of others and sense of security in the company of others can be gained through positive peer relationships. It can also increases confidence, develop social skills and competencies. Chances to practice and improve social skills, develop empathy and discuss moral dilemmas are gained through the social support of peers (Lim, Baharuddin \& Tan, 2013; Pitman \& Scharfe, 2010; Schnyders, 2012; Strohmeier, Fandrem \& Spiel, 2012).

Studies points to the fact that being accepted in peer group is crucial to early adolescents (Goresse, 2015). Research on the level of peer attachment indicates that having friends in middle school and being socially accepted relates positively to higher prosocial and lower antisocial behaviour in school (Lee \& Hankin, 2009), better academic achievement (Wentzel, Barry, \& Caldwell, 2004), lower emotional problems (Wentzel \& Caldwell, 1997), and better school adjustment (Wentzel, Barry, \& Caldwell, 2004).

The current and future well-being of adolescents is linked to peer attachment by being the important sources of affection, intimacy, feelings of inclusion, dependable alliance and enhancement of self-worth (Oberle, Schonert-Reichl \& Thomson, 2010). Research shows that having positive peer attachment in early elementary school years helps acceptance in the later school years and promote social competence (Hay, 2005) while poor attachment is related with negative outcomes such as delinquency, early school withdrawal, mental health problems and substance abuse (Woodward \& Fergusson, 1999). Therefore, experiencing supportive and close relationships with peers are seen to be important for the development of adolescent positive well-being.

\section{Objective of the Study}

It is essential to identify factors that may influence the positive (well-being) of adolescents early to ensure they are given proper guidance to lead a better accomplished life that may facilitate a successful transition from childhood through adolescence and into adulthood. Research is still needed to assess adolescent positive well-being not only from the standpoint of the absence of problems but also identifying positive indicators of well-being (Pace \& Zappulla, 2009). Previous research on peer attachment have focused on negative outcomes (Feinberg et al., 2013; Finan, 2016; Giletta, et al., 2012; Gorrese, 2015) so in order to foster the psychological health and social competence of adolescents that may-potentially prevent health risk behaviours such as substance abuse, it is important to strengthen peer attachment (Feinberg et al., 2013). Hence, this study examines the importance of the level peer attachment on the positive development of adolescents.

Previous studies on the level of early adolescence peer attachment had focused on understanding the negative aspects their relationships including peer rejection, bullying and victimization, mental illness, dropping out of school, and behavioural problems (Dijkstra, Lindenberg \& Veenstra, 2007; Gazelle \& Druhen 2009; Trentacosta \& Shaw 2009). Although there are advance understanding of the negative 
influence of peer attachment on the well-being of early adolescents, there is a paucity of information on the positive aspects of peer attachments (Oberle, Schonert-Reichl \& Thomson, 2010). Researchers have suggested taking a strengths-based approach in understanding adolescent development by including positive dimensions of wellbeing in examining influence of adolescent peer attachments (Benson, Scales, Hamilton, Sesma, Hong \& Roehlkepartain, 2006; Damon, 2004). This perspective strives to observe the positive features of human development.

In the positive youth development framework (Lerner, 2005), gender differences are seen as a factor that could affect adolescent's positive well-being. Boys and girls tend to take different behavioural and cognitive roles in life. It is more common for girls to develop emotional problems such as sadness, anxiety, and anger whereas boys develop externalizing problems such as aggressiveness and dominance (Garaigordobil, Maganto, Perez \& Sansinennea, 2009). Research has found that gender can be an important moderator of the relationship between familial and social relationships and adolescent positive well-being (Albert, 2003). However, empirical findings to-date have been inconsistent and contradictory with regard to the specific role gender plays in adolescent positive well-being (Albert, 2003). This study examines gender as a moderating factor for the relationship between peer attachment and adolescent positive well-being.

It is essential to identify the indicators for positive well-being, and in the process this study aims to address the following objectives:

Does the level of peer attachment contribute to adolescent positive well-being?

Does gender moderate relationships between peer attachments with adolescent positive well-being?

\section{Literature Review}

One of the most obvious changes in adolescence is its transition from prioritizing family to peer group (American Psychological Association, 2002). Adolescent peer attachments are grounded in the desire for emotional support and security, and during this period much time is spent among each other for the support that such proximity affords (Schoeps, et al., 2020). Nickerson and Nagle (2005) studied grade four, six, and eight students to compare the difference in parent and peer attachments to establish exactly when peers figure in the attachment hierarchy and it is reported that during early adolescent rather than the late childhood phase is when less trust and communication is reported with parents, and when peers seek to fulfill attachment needs and safe havens.

Multiple factors of peer attachment is related to adolescent development (Kingery, et al., 2010; Parker, et al., 2006) and the friendship they share are both an important and unique aspect in their development (Hussong, 2000; Kingery, et al., 2010). Close friendships have a greater influence on adolescent's development (Hartup 1996), and strong peer attachment helps to improve their social skills development (Gorrese, 
2015). In general, among friendships with high positive qualities, studies have found lower rates of peer victimization (Hodges, et al., 1999), and depressive and anxiety symptom (Roelofs, Onckels \& Muris, 2013; Ruijten et al., 2011). Moreover, negative interactions among close friends may lead to increased negative peer judgments and raise in distress and discomforts (La Greca \& Harrison, 2005).

There is a need to acknowledge the positive and negative feature of adolescent attachment especially those that increase risks or shield against rise in internalizing symptoms. In this respect, attachment theory (Monaco, et al., 2019) plays an important function in understanding the psychological, emotional and social adjustments of adolescents. Attachment theory allows for an evaluation of the basic ways in which emotions, behaviours and cognitions are processed, and how they are connected to the past, present, and future impacting attachments and effective bonds (Zimmermann, 2004).

Positive peer attachment during adolescence is generally related to psychosocial adjustment (Vagos \& Carvalhais, 2020). Adolescents who are acknowledged by their peers and have a reciprocal relationship with their peers, tends to have a better level of self image and school experience (Hansen, Nangle \& Meyer, 1998). In comparison, social isolation by peers are associated with a variety of negative behaviours (Nangle \& Hansen, 1998) and a greater risk for psychosocial difficulties was found amongst adults who experienced interpersonal problems during adolescence (Poudel, Sharma, Gautam \& Poudel, 2016). Greater levels of social support is needed during the adolescence period where adolescents are inclined to share their innermost feelings and thoughts with their peers (Gunasegaran, et al. 2018).

Studies show that both adolescent girls and boys place great emphasis on intimacy, that as a primary quality of friendship, private thoughts and feelings can be freely shared with their peers (Bakken \& Romig, 1992, Rose \& Rudolph, 2006). Gender differences also exist with respect to the kinds of activities girls and boys engage in most often with their friends. In general, boys prefer action-oriented pursuits whilst girls spend greater time chatting together (Spencer, 2008). Irrespective of which behaviour is engaged in, both boys and girls gives equal importance to certain values of friendship such as trustworthiness, loyalty and frankness (Nega, 2014).

Adolescents are assisted by peers in learning about solving problems as well as provide important support in times of stress. Such learning in handling the needs and emotions of other, gives adolescents a chance to learn, practice and enhance their social skills. Problematic peer relationships and conflict can impair an adolescents' emotional and social well-being. This research thus addresses peer attachment in the effort to understand adolescent positive well-being.

\section{Methodology}

This is a cross-sectional study using a quantitative approach in the correlation research design in determining the relationship between peer attachment and 
adolescent positive well-being. The study involved 4007 th grade students from government schools in the Federal Territory of Kuala Lumpur and the state of Selangor. The total number of respondents for this study was 400 comprising 216 females and 184 males. The study comprised respondents from the three major ethnic groups in Malaysia which are Malay (176 respondents), Chinese (120), and Indians (104). The majority of parents of the respondents were aged 41 to 50 years. The statistics also show that most respondents had a monthly family income below RM6,000. The data was collected using self administered questionnaires, and the measurement tools used for the study were the Positive Youth Development Scale (Geldhof et al., 2013) and Inventory of Peer and Parent Attachment (Armsden \& Greenberg, 1987).

\section{Adolescent Positive Well-being}

The Positive Youth Development Scale was used as it is easily computable and can provide a single number representing an adolescent's global level of positive development consisting of the 5Cs (Competence, Confidence, Connection, Character, and Caring) (Geldhof et al., 2013). The items for the scale were drawn from multiple sources and scored accordingly using different metrics. Not all items used the 5-point Likert response format. There was a total of 34 items in the Positive Youth Development Short Form Scale and scoring averaged the individual 5C scores to achieve an overall Positive Youth Development Scale score with a higher score representing better positive well-being. The Cronbach's Alpha value showed 0.734 which indicated a strong internal consistency.

\section{Peer Attachment}

Peer attachment was assessed using the Inventory of Parent and Peer Attachment (IPPA) that is comprised of 25 items. This inventory was developed to assess adolescents' perceptions of the positive and negative dimension of relationships with their peers (Armsden \& Greenberg, 1987). The Cronbach's Alpha value for this scale showed 0.850 which indicated strong internal consistency.

\section{Findings}

\section{Peer Attachment and Adolescent Positive Well-being}

A pearson correlation analysis was conducted to analyse the link between peer attachment and adolescent positive well-being. Later multiple regression analysis was conducted to determine whether peer attachment was a predictor variable for adolescent positive well-being. The results of the Pearson correlations (Table 1) show a significant result $(\mathrm{r}=0.232, \mathrm{p}<0.05)$ which indicates peer attachment is associated with adolescent positive well-being. In addition, the findings of multiple regression analysis found that peer attachment is a predictor of adolescent positive well-being $(\beta=0.369, \mathrm{p} \leq 0.01)$ as shown in Table 2 . 


\section{Adolescent Positive well-being}

To test the hypothesis that gender moderates the relationship between peer attachment and adolescent positive well-being, a hierarchical multiple regression analysis was conducted using "Model 1" in Macro Process (Table 3). Firstly, two variables of peer attachment and gender were included and they accounted for a significant amount of variance in adolescent positive well-being at $\mathrm{R}^{2}=0.157, \mathrm{~F}(2$, $397)=37.09, \mathrm{p}<.001$. To avoid potentially problematic high multicollinearity with the interaction term, the variables were centered and an interaction term was created between peer attachment and gender (Aiken \& West, 1991).

The interaction term was added to the regression model, which accounted for a significant portion of the variance in adolescent positive well-being at $\Delta \mathrm{R}^{2}=0.075, \Delta \mathrm{F}$ $(1,396)=38.563, \mathrm{P}<0.001, \mathrm{~b}=0.566, \mathrm{t}(396)=5.739, \mathrm{p}<0.001$. An examination of the interaction plot (Figure 4.6) in the overall model showed that girls had higher positive well-being compared to boys. The result for girls showed that higher attachment with their peers led them to have higher positive well-being; however, the well-being of boys were similar regardless of the level of attachment with their peers.

Table 1. Correlation between Maternal and Paternal Attachment with Adolescent Positive Well-being

Note: **

\begin{tabular}{llll} 
Variable & 1 & 2 & 3 \\
\hline
\end{tabular}

1. Positive well-being

1

2. Peer Attachment

$.232^{* *}$

1

Correlation is significant at the 0.01 level

Table 2. Multiple Regression Analysis between Maternal and Paternal Attachment with Adolescent Positive Well-being

\begin{tabular}{|c|c|c|c|c|c|}
\hline \multirow[b]{2}{*}{ Model } & \multicolumn{2}{|c|}{$\begin{array}{l}\text { Unstandardized } \\
\text { Coefficients }\end{array}$} & $\begin{array}{l}\text { Standardized } \\
\text { Coefficients }\end{array}$ & \multirow[b]{2}{*}{$t$} & \multirow[b]{2}{*}{ Sig. } \\
\hline & $B$ & $\begin{array}{l}\text { Std } \\
\text { Error }\end{array}$ & $\operatorname{Beta}(\beta)$ & & \\
\hline (Constant) & 69.462 & 3.463 & & 23.163 & .000 \\
\hline Peer Attachment & 0.350 & 0.044 & 0.369 & 3.407 & .000 \\
\hline
\end{tabular}


Table 3: Interaction between Gender, Peer Attachment and Adolescent Positive Wellbeing

\begin{tabular}{llllllllll} 
& & \multicolumn{10}{c}{ Model } & $R$ & $R^{2}$ & Adj $R^{2}$ & SEE & $R^{2}$ & $F$ & $d f 1$ & $d f 2$ & $p$ \\
\hline 1 & $.397^{a}$ & .157 & .153 & 11.661 & .157 & 37.09 & 2 & 397 & .000 \\
2 & $.482^{b}$ & .232 & .226 & 11.145 & .075 & 38.56 & 1 & 396 & .000 \\
\hline
\end{tabular}

Note: $b=0.566, t(396)=5.739, p<0.001$

a. Predictors: (Constant), Peer Attachment, Gender

b. Predictors: (Constant), Peer Attachment, Gender, genderxIPPAP

\section{0 \\ 105 \\ 100 \\ 95 \\ 90 \\ 85 \\ 80}

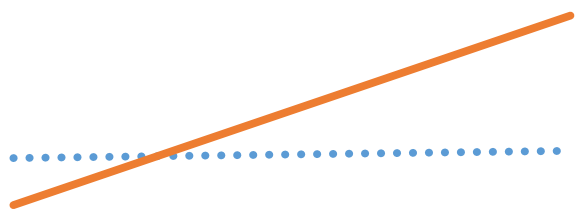

Low Peer Attachment

High Peer Attachment

...... Male Female

Figure 1: Interaction Plot for the Moderation Role of Gender on the Relationship between Peer Attachment and Adolescent Positive Well-being

\section{Discussion}

\section{Peer Attachment and Adolescent Positive Well-being}

The results of the study it was found that there is a significant link between peer attachment and adolescent positive well-being. It was also found that peer attachment was a predictor for adolescent's positive well-being. It could be explained that peer groups have been found to serve various important funtions during adolescents (Gorrese, 2015). During the period of adolescence, peer attachment can help form the sense of their identity. Adolescents develop moral judgments and values through identification with peers which determines how they differ from their parents. Information about themselves and the world outside of the family are gained through the relationship with their peers (Oberle, Schonert-Reichl \& Thomson, 2010). 
This finding is supported by previous studies where it was found that peers are of central importance for social functioning, academic achievement and psychological well-being of adolescents (Hay, 2005). The degree to which an individual is liked or disliked by his or her peers, is not only related to early adolescent well-being but peer rejection can predict adjustment problems in later adolescence and adulthood (Woodward \& Fergusson, 1999).

Continuous high level peer conflict may lead to problematic behaviours in some adolescents, and those who are unable to manage their problems appropriately may become isolated and rejected by their peers which leads to negative outcome. Secure peer attachment plays a greater role in positive development (Hartup, 1996) such as encouraging enhancement of social skills (Gorrese, 2015) and providing important interpersonal experiences not available in other social interactions and contexts (Poudel, et al., 2016). It can be summarised that the level of peer attachment during adolescence therefore, is significant in the promotion of positive development in adolescents.

\section{Moderation Role of Gender on the Relationship between Peer Attachment and Adolescent Positive well-being}

Adolescents who have strong bonds with others are generally more impulsive in response to situational demands, flexible in their expression of feelings and would be able to solve their problems by using their better in social networks (SeiffgeKrenke, 2006). Adolescents who had the ability to recognise and acknowledge their negative emotions, are capable of improving both interpersonal competence and successful social adjustments (Laible, 2007). In contrast, insecure adolescents exhibit withdrawal symptoms, mistrust of others and difficulty in seeking support during the period of successful transition into adolescence (Larose \& Bernier 2001).

Adolescents would be able to improve their emotional regulation skills by having secure peer attachment. Therefore, it might be expected that the strength and security of adolescent peer attachment relationships are related to their positive well-being because of the effects that attachment relationships with peers have on the development of emotion-expression and regulation.

The findings of this study concur with previous research that reports how females are more attached to their peers than males (Richards, McGee, Williams, Welch \& Hancox, 2010) and display higher trust and more deep communication with them (Gullone \& Robinson, 2005; Ruijten, Roelofs \& Rood, 2011; Song, Thompson \& Ferrer, 2009). Girls' friendships typically are deeper and more interdependent than that of boys; furthermore, in their friendships girls reveal a greater need for nurturance, more empathy and the desire for and ability to sustain intimate relationships (Gorrese \& uggieri, 2012). This may be attributive factors for their higher positive well-being compared to boys. In summary this result indicates that 
gender does moderate the relationship between peer attachment and adolescent positive well-being.

\section{Conclusion}

This study showed that peer attachment is a significant predictor of adolescent positive well-being. The findings supports the view of the theories used as the baseline for the study which are the Positive Youth Development Framework, Family System Theory, and Attachment Theory. The study contributes to understanding the interrelationships between family and social environment during early adolescence and connects Family System Theory and Attachment Theory with the Positive Youth Development Framework, particularly in balancing the theoretical work that emphasizes that adolescent positive well-being is about the positive relationship with friends (Burton \& Jarrett, 2000; Leventhal \& Brooks-Gunn, 2000). This study found that gender moderates the relationship between peer attachment and adolescent positive well-being. It also notes that girls generally did have higher positive well-being compared to boys.

The information from this study adds to the existing literature on peer attachment during early adolescence as most of the past studies focused on negative outcomes and less focus was given on positive development (Feinberg, et al., 2013; Finan, 2016; Giletta, et al., 2012; Gorrese, 2016). The findings of this study had found that peer attachment were important predictors of adolescent positive well-being. Limitations in this study include population and ecological validity. Due to the demographic characteristics of the current sample, it is likely that implications may only apply to adolescents in the cultural majority, raised in two-parent homes, and living within a middle-to-high social economic status community. Further, the study sample is limited to adolescents aged 13 in Kuala Lumpur and Selangor. In addition, this study included measures of several individual characteristics (age, gender, ethnicity, years of education, and monthly income) but not individual-level measures such attitudes, behaviours, and personalities of adolescents and parents.

Greater insight and relevance could be achieved if future studies employed a wider sampling range. To operationalize fully the interactions of adolescents and families future research can incorporate the individual characteristics of participating adolescents and their parents to arrive at a richer understanding of factors influencing adolescent positive well-being.

\section{Reference}

[1] Aiken, L. S., \& West, S. G. (1991). Multiple regression: Testing and interpreting interactions. Thousand Oaks, CA: Sage.

[2] Albert, A. S. B. (2003). Parental and peer support as predictors of depression and self esteem among late adolescents: An attachment theory perspective. 
[3] American Psychological Association. (2002). Developing Adolescents: A reference for professional. Retrieved from https://www.apa.org/pi/families/resources/develop.pdf

[4] Armsden, G. C., \& Greenberg, M. T. (1987). The Inventory of Parent and Peer Attachment: Relationships to well-being in adolescence. Journal of Youth and Adolescence, 16 (5), 427-454.

[5] Bakken, L., \& Romig, C. (1992). Interpersonal needs in middle adolescents: Companionship, leadership, and intimacy. Journal of Adolescence, 15, 301316.

[6] Benson, P. L., Scales, P. C., Hamilton, S. L., Sesma, A., Jr., Hong, K. L., \& Roehlkepartain, E. C. (2006). Positive youth development so far: Core hypotheses and their implications for policy and practice. Search Institute Insights and Evidence, 3, 1-13.

[7] Borelli, J. L., \& Prinstein, M. J. (2006). Reciprocal, longitudinal associations among adolescents' negative feedback-seeking, depressive symptoms, and peer relations. Journal of Abnormal Child Psychology, 34, 154-164.

[8] Bornstein, M.H., Hahn, C. S., \& Hayness, O. M. (2012). Social competence, externalizing, and internalising behavior adjeustment from early childhood through early adolescence: Developmental cascades. Dev Psychopathol. 22(4): 717-735. Retrieved from https://www.ncbi.nlm.nih.gov/pmc/articles/PMC3412561/

[9] Burk, W. J., \& Laursen, B. (2005). Adolescent perceptions of friendship and their associations with individual adjustment. International Journal of Behavioral Development, 29, 156-164.

[10] Burton, L. M., \& Jarrett, R. L., (2000). In the mix, yet on the margins: The place of families in urban neighborhood and child development research. Journal of Marriage and Family, 62(4), 1114-1135.

[11] Damon, W. (2004). What is positive youth development? Annals of the American Academy of Political and Social Science, 591, 13-24.

[12] Department of Statistics Malaysia. (2016). Children statistics, Malaysia 2016. Retrieved from https://www.dosm.gov.my/v1/index.php?r=column/pdfPrev\&id=NVYwaEt wM21MempVbWpBZFpxOFZHZz09

[13] Dijkstra, J. K., Lindenberg, S., \& Veenstra, R. (2007). Same-gender and crossgender peer acceptance and peer rejection and their relation to bullying and helping among preadolescents: Comparing predictors from genderhomophily and goal-framing approaches. Developmental Psychology, 43, 1377-1389.

[14] Eccles, J. S. (1999). The development of children ages 6 to 14. The Future of Children: When School is Out, 9, 30-44. Retrieved from http://www.rcgd.isr.umich.edu/garp/articles/eccles99n.pdf

[15] Feinberg, M. E., Sakuma, K. L., Hostetler, M. \& McHale, S. M. (2013). Enhancing sibling relationships to prevent adolescent problem behaviors: 
Theory, design and feasibility of siblings are special. Evaluation and Program Planning, 36, 97-106

[16] Finan, L. J. (2016). Parent, peer, and sibling relationship factors and depression in adolescence and emerging adulthood: A growth curve analysis. Retrieved from https://ezproxy.um.edu.my:2997/dissertations/docview/1818472036/pre viewPDF/B5E3C436C7954F56PQ/1?accountid=28930

[17] Garaigordobil, M., Maganto, C., Perez, J. I., \& Sansinenea, E. (2009). Gender differences in socioemotional factors during adolescence and effects of a violence prevention program. Journal of Adolescence Health, 44, 468-477.

[18] Gazelle, H., \& Druhen, M. J. (2009). Anxious solitude and peer exclusion predicts social helplessness, upset affect, and vagal regulation in response to behavioral rejection by a friend. Developmental Psychology, 45, 1077-1096

[19] Geldhof, G.J., Bowers, E.P., Boyd, M.J., Mueller, M.K., Napolitano, C.M., Schmid, K.L., Lerner, J.V. \& Lerner, R.M. (2013). Creation of short and very short measures of the five cs of positive youth development. Journal of Reasearch on Adolescence, 24(1), 163-176.

[20] Giletta, M., Scholte, R., Prinstein, M., Engels, R., Rabaglietti, E., \& Burk, W. (2012). Friendship context matters: Examining the domain specificity of alcohol and depression socialization among adolescents. Journal of Abnormal Child Psychology, 40, 1027-1043.

[21] Gorrese, A. (2015). Peer attchment and youth internalising problems: A meta analysis. Child Youth Care Forum, 45, 177-204.

[22] Gorrese, A. \& Ruggieri, R. (2012). Peer attachment: A meta-analystic review of gender and age differences and associations with parent attachment. Journal of Youth and Adolescence, 41, 650-672.

[23] Gullone, E., \& Robinson, K. (2005). The Inventory Of Parent And Peer Attachment-Revised (IPPA-R) for children: A psychometric investigation. Clinical Psychology \& Psychotherapy, 12, 67-79.

[24] Gunasegaran, K., Hatnin D, \& Melissa, W, M. (2018). Professional Learning Community (Plc) Practices And Educators Efficacy (Ee) Level Among The Form Six Educators International Journal of Education, Learning and Development, Vol 6, Issue 9, 89 - 97.

[25] Hansen, D. J, Nangle, D. W., \& Meyer, K. A. (1998). Enhancing the effectiveness of social skills interventions with adolescents. Education and Treatment of Children, 21, 489-513.

[26] Hartup, W. W. (1996). The company they keep: Friendships and their developmental significance. Child Development, 67, 1-13.

[27] Hay, D. F. (2005). Early peer relations and their impact on children's development. Encyclopedia on Early Children Development. Retrieved from http://www.child-encyclopedia.com/sites/default/files/textesexperts/en/829/early-peer-relations-and-their-impact-on-childrensdevelopment.pdf 
[28] Hussong, A. M. (2000). Perceived peer context and adolescent adjustment. Journal of Research on Adolescence, 10, 391-415.

[29] Hodges, V. E., Boivin, M., Vitaro, F., \& Bukowski, W. (1999). The power of friendship: Protection against an escalating cycle of peer victimization. Developmental Psychology, 35, 94-101.

[30] Kingery, J. N., Erdley, C. A., Marshall, K. C., Whitaker, K. G., \& Reuter, T. R. (2010). Peer experiences of anxious and socially withdrawn youth: An integrative review of the developmental and clinical literature. Clinical Child and Family Psychology Review, 13, 91-128.

[31] Koepke, S., \& Denissen, J. J. A. (2012). Individuation and identity development in adolescence and emerging adulthood: Conceptual clarifications and an integrative model. Developmental Review, 32, 67-88.

[32] La Greca, A. M., \& Harrison, H. M. (2005). Adolescent peer relations, friendships, and romantic relationships: Do they predict social anxiety and depression. Journal of Clinical Child and Adolescent Psychology, 34, 49-61.

[33] Laible, D. (2007). Attachment with parents and peers in late adolescence: Links with emotional competence and social behavior. Personality and Individual Differences, 43, 1185-1197.

[34] Larose, S., \& Bernier, A. (2001). Social support processes: Mediators of attachment state of mind and adjustment in late adolescence. Attachment \& Human Development, 3, 96-120

[35] Lee, A., \& Hankin, B. L. (2009). Insecure attachment, dysfunctional attitudes, and low self esteem predicting prospective symptoms of depression and anxiety during adolescence. Journal of Clinical Child and Adolescence Psychology, 38(2), 219-231

[36] Lee, Y.P. (2010). Children suffering from stress and depression. Retrieved from

http://www.dhrramalaysia.org.my/dhrramalaysia/index.php?option=com_c ontent\&view=article\&id=307:star20-of-children-suffering-stress-anddepression-liow\&catid=49:psychological-news

[37] Lerner, R.M. (2005). Promotig positive youth development: Theoretical and empirical bases. Institute for Applied Research in Youth Development Tuft University. Retrieved from https://ase.tufts.edu/iaryd/documents/pubPromotingPositive.pdf

[38] Lerner, R. M., Lerner, J. V., Lewin-Bizan, S., Bowers, E. P., Boyd, M. J., Mueller, M. K., Schmid, K. L., \& Napolitano, C. M. (2011). Positive youth development: Process, programs and problematics. Journal of Youth Developments, 6(3).

[39] Leventhal, T, \& Brooks-Gunn, J. (2000). The neighborhoods they live in: The effects of neighborhood residence on child and adolescent outcomes. Psychological Bulletin, 126(2), 309-337.

[40] Lim, H. J., Baharuddin, R. \& Tan, J. P. (2013). Percieved parental warmth and depression in early adolescents: path analysis on the role of self esteem as a mediator. Pertanika Journals of Social Sciences and Humanities. 21(1), 165- 
178.

[41] McElhaney, K. B., \& Allen, J. P. (2012). Sociocultural perspectives on adolescent autonomy. Retrieved from

http://people.virginia.edu/ psykliff/Teenresearch/Publications_files/Socio cultural\%20Perspectives\%20on\%20Adolescent\%20Autonomy\%20.pdf

[42] Millings, A., Buck., R., Montgomery, A., Spears, M., \& Stallard, P. (2012). School connectedness, peer attachment, and self-esteem as predictors of adolescent depression. Journal of Adolescence. 35 (4): 1061-1067. Retrieved from

https://www.sciencedirect.com/science/article/abs/pii/S01401971120003 58

[43] Mónaco, E., Schoeps, K., \& Castilla, I. M. (2020). Attachment styles and well being in adolescents: How does emotional development affect this relationship?. Int J Environ Res Public Health. 16(14): 2554. Retrieved from https://www.ncbi.nlm.nih.gov/pmc/articles/PMC6678901/

[44] Nangle, D. W., \& Hansen, D. J. (1998). New directions in the application of social-skills interventions with adolescents: Introduction to the special section. Faculty Publications, Department of Psychology. Retrieved from http://digitalcommons.unl.edu/cgi/viewcontent.cgi?article=1073\&context= psychfacpub

[45] Nega, T. (2014). Peer group influence, alcohol consumption and academic self esteem of adolescents in North Shoa Zone: The case of Ataye Secondary School. Retrieved from

http://etd.aau.edu.et/bitstream/123456789/7485/1/1.\%20Tilaye\%20Neg a.pdf

[46] Nickerson, A. B., \& Nagle, R. J. (2005). Parent and peer attachment in late childhood and early adolescence. American Journal of Early Adolescence, 25, 223-249.

[47] Oberle, E., Schonert-Reichl, K.A., \& Thomson, K.C. (2010). Understanding the link between social and emotional well being and peer relations in early adolescence: Gender-specific predictors of peer acceptance. Journal of Youth and Adolescence, 39, 1330-1342.

[48] Oldfield, J., Humphrey, N., \& Hebron, J. (2016). The role of parental and peer attachment relationships and school connectedness in predicting adolescent mental health outcomes. Child Adolesc Ment Health. 21(1): 21-29.

[49] Pace, U., \& Zappulla, C. (2009). Identity processes and quality of emotional autonomy: The contribution of two developmental tasks on middleadolescents' subjective well-being. An International Journal of Theory and Research, 9, 323-340.

[50] Parker, J. G., Rubin, K. H., Erath, S. A., Wojslawowicz, J. C., \& Buskirk, A. A. (2006). Peer relationships, child development, and adjustment: A developmental psychopathology perspective. Retrieved from https://www.researchgate.net/publication/235910155_Peer_Relationships_ 
Child_Development_

[51] Pitman, R., \& Scharfe, E. (2010). Testing the function of attachment hierarchies during emerging adulthood. Personal Relationships, 17, 201216.

[52] Poudel, A., Sharma, C., Gautam, S., \& Poudel, A. (2016). Psychosocial problems among individuals with substance use disorders in drug rehabilitation centers, Nepal. Substance Abuse Treatment and Prevention Policy, 11, 28

[53] Preusse, K. (2008). Fostering prosocial behavior in young children. Early Childhood news. Rectrieved from http://www.earlychildhoodnews.com/earlychildhood/article_view.aspx?Art icleId $=566$

[54] Richards, R., McGee, R., Williams, S. M., Welch, D., \& Hancox, R. J. (2010). Adolescent screen time and attachment to parents and peers. Archives of Pediatrics \& Adolescent Medicine, 164, 258-262.

[55] Roelofs, J., Onckels, L., \& Muris, P. (2013). Attachment quality and psychopathological symptoms in clinically referred adolescents: The mediating role of early maladaptive schema. Journal of Child and Family Studies, 22, 377-385

[56] Ruijten, T., Roelofs, J., \& Rood, L. (2011). The mediating role of rumination in the relation between quality of attachment relations and depressive symptoms in non-clinical adolescents. Journal of Child Family Studies, 20, 452-459.

[57] Schnyders, C. (2012). Parental and Peer Attchment as Predictors of the Percieved Experience of Emerging Adulthood Among Undergraduates between the Ages of 18-20: A Multiple regression Study. Retrieved from https://etd.ohiolink.edu/rws_etd/document/get/kent1341242639/inline

[58] Schoeps, K., Mónaco, E., Cotolí, A., \& Castilla, I. M. (2020). The impact of peer attachment on prosocial behavior, emotional difficulties and conduct problems in adolescence: The mediating role of empathy. Plos One. Retrieved from https://journals.plos.org/plosone/article?id=10.1371/journal.pone.022762 7

[59] Schonert-Reichl, K. A. (1999). Relations of peer acceptance, friendship, adjustment, and social behavior to moral reasoning during early adolescence. Journal of Early Adolescence, 19, 249-279

[60] Seiffge-Krenke, I. (2006). Coping with relationship stressors: The impact of different working models of attachment and links to adaptation. Journal of Youth and Adolescence, 35, 25-39

[61] Sentse, M., Lindenberg, S., Omvlee, A., Ormel, J., \& Veenstra, R. (2010). Rejection and acceptance across context: Parents and peers as risks and buffers for early adolescent psychotherapy. The TRAILS study. Journal of Abnormal Child Psychology, 38(1), 119-130. 
[62] Song, H. R., Thompson, R. A., \& Ferrer, E. (2009). Attachment and selfevaluation in Chinese adolescents: Age and gender differences. Journal of Adolescence, 32, 1267-1286.

[63] Steinberg, L. (2005). Cognitive and affective development in adolescence. Trends in Cognitive Science, 9, 69-74

[64] Strohmeier, D., Fandrem, H., \& Spiel, C. (2012). The need for peer acceptance and affiliation as underlying motive for aggressive behavior and bullying others among immigrant youth living in Austrua and Norway. Journal of Psychology, 28(3), 695-704

[65] Trentacosta, C. J., \& Shaw, D. S. (2009). Emotional self-regulation, peer rejection, and antisocial behavior: Development associations from early childhood to early adolescence. Journal of Applied Developmental Psychology, 30, 356-365.

[66] Vagos, P., \& Carvalhais, L. (2020). The impact of adolescents' attachment to peers and parents on aggressive and prosocial behavior: A short-term longitudanal study. Frontiers Psychology. Retrieved from https://www.frontiersin.org/articles/10.3389/fpsyg.2020.592144/full

[67] Wentzel, K. R., Barry, C., \& Caldwell, K. (2004). Friendships in middle school: Influences on motivation and school adjustment. Journal of Educational Psychology, 96, 195-203.

[68] Wentzel, K. R., \& Caldwell, K. A. (1997). Friendships, peer acceptance, and group membership: Relations to academic achievement in middle school. Child Development, 68, 1198-1209.

[69] Woodward, L. J., \& Fergusson, D. M. (1999). Childhood peer relationship problems and psychosocial adjustment in late adolescence. Journal of Abnormal Child Psychology, 27, 87-104

[70] Wong, S. Y., \& Lua, P. L. (2011). Anxiety and depressive symptoms among cin the east coast of peninsular Malaysia: A rural exploration. Retrieved from http://www.mjpsychiatry.org/index.php/mjp/article/viewFile/143/119

[71] Youngblade, L. M., Theokas, C., Schilenberg, J., Curry, L., Huang, I. C. \& Novak, M. (2007). Risk and Promotive Factors in Families, Schools and Communities: A Contextual Model of Positive Youth Development in Adolescence. Pediatrics, 119(1).

[72] Zimmerman, P. (2004). Attachment represents and characteristics of friendship relations during adolescence. Journal of Exploratory Child Psychology, 88, 83-101. 